Boise State University

ScholarWorks

Criminal Justice Faculty Publications and

Presentations

Department of Criminal Justice

$1-10-2011$

Genetic and Environmental Influences in

Delinquent Peer Affiliation: From the Peer

Network Approach

Ilhong Yun

Boise State University

Jinseong Cheong

Soonchunhyang University

Anthony Walsh

Boise State University 


\title{
Genetic and Environmental Influences in Delinquent Peer Affiliation: From the Peer Network Approach
}

\author{
Ilhong Yun \\ Boise State University \\ Jinseong Cheong \\ Soonchunhyang University \\ Anthony Walsh \\ Boise State University
}

\begin{abstract}
Mainstream criminologists have long maintained that delinquent peer group formation is largely a function of family-environmental variables, and have ignored self-selection into peer groups because of genetic proclivities. A small number of recent studies, however, suggest that genes are implicated in delinquent peer affiliation. Given the potentially far-reaching implication of such research findings, the authors replicate Beaver, Wright, \& DeLisi's (2008) study, among others, using a direct measure of peer delinquency. That is, the authors analyze the Add Health genetic data employing a measure of peer delinquency which is based on the delinquency counts reported by peers themselves rather than respondents' self-reports. Even employing this alternative measure, their results clearly support the original study, providing further evidence of genetic underpinnings of delinquent peer group formation.
\end{abstract}

Key Word: biosocial criminology, gene environment interaction, gene environment correlation, delinquent peers

Criminology has been largely dominated by sociological paradigms during the better part of the twentieth century. The typical criminologist underscores the saliency of sociological factors as the primary independent variables, while being less likely to entertain the possibility that biological factors may also be responsible for the creation of criminal and delinquent behavior (Moffitt, 2005; Walsh, 2009). Contemporary criminologists are trained more than likely in the sociological paradigm (Cooper, Walsh, \& Ellis, 2010) that emphasize such concepts as social learning, subcultures, bonding, socialization, and poverty, and thus tend to de-emphasize theories that contain propositions about genes, neurotransmitters, and hormones.

However, great strides have been made in the realm of the biological sciences in recent decades in unraveling causes of human behaviors. This progress has been so remarkable that it led Robinson to point out in a somewhat argumentative manner that: "The biological sciences have made more progress in advancing our understanding about behavior in the last 10 years than sociology has made in the past 50 years" (2004, p. 4). Although such a seemingly adversarial stance such as Robinson's does not seem desirable in advancing science, findings from behavioral genetics, molecular genetics, and neuroscience studies have indeed converged to demonstrate that all types of human behavior, including crime and delinquency, are at least partially influenced by genetic factors (Moffitt, 2005; Scarr \& McCartney, 1983; Shanahan \& Hofer, 2005).

In recent years, the field of criminology has witnessed an emergence of a small group of researchers, who actively incorporate biological sciences into criminology. These researchers are advancing the biosocial paradigm to the forefront of the discipline (Cullen, 2009; Walsh, 2009). Their works touch on a variety of correlates of crime and delinquency that have been examined by sociology-based criminologists, including childhood abuse, parental bonding, low self-control, drug and alcohol abuse, gang membership, victimization, and even delinquent peer association (Beaver, Delisi, Vaughn, \& Barnes, 2009; Vaughn et al, 
This is an author-produced, peer-reviewed version of this article. The final, definitive version of this document can be found online at Youth Violence and Juvenile Justice, published by SAGE. Copyright restrictions may apply. DOI: 10.1177/1541204010388527

2009; Vaske, Beaver, Wright, Boisvert, \& Schnupp, 2009; Beaver, Wright, \& DeLisi, 2008). Their studies consistently reveal a clear pattern, which demonstrates that crime and delinquency are not a product of sociological factors only, but a product of the interplay between sociological and genetic factors.

Among these recent studies, our interests lies in the study of Beaver and colleagues (2008) which revealed that affiliating with delinquent peers is significantly and robustly influenced by a variant of the dopamine transporter gene (DAT1). The reasons we exhibit interests in this particular study are three-fold. First, delinquent peer association has long been regarded as the most important correlate of one's own delinquent involvement by many mainstream criminologists (Agnew, 1991; Akers, 1998; Matsueda \& Anderson, 1998; Warr, 2002). Regarding the causal factors that lead one to delinquent peers, however, most criminologists focused solely on social contexts such as family-environmental factors (Harris, 1998; Hirschi, 1969; Warr, 2002). Almost no attention has paid to potential roles played by genes. Thus, the Beaver et al.'s (2008) finding that genes underlie delinquent peer association can have one of the most far-reaching implications in criminology.

Second, a small number of biologically-trained scholars have hypothesized that genes as well as sociological variables are implicated in adolescents' self-selection into antisocial peer groups (Plomin, DeFries, \& Loehlin, 1977; Scarr \& McCartney, 1983; Walsh, 2002). However, testing such a hypothesis and revealing implication of a particular candidate gene have been beyond empirical reach until recently simply because requisite data were unavailable. In this context, Beaver and colleague's study is of great theoretical and empirical value in that it is the first and only to establish a statistically meaningful association between homophily for delinquency and a specific genetic polymorphism.

Third and more importantly, despite the increasing volume of behavioral genetics research examining correlations between candidate genes and certain phenotypes, replication studies in this area frequently fail to produce the original findings (Faraone, Doyle, \& Biederman, 2001; Kotler et al., 2000). Moreover, molecular genetics studies in the realm of criminology exhibits a glaring lack of such replication attempts. In this context, we attempt to replicate Beaver et al.'s (2008) findings utilizing an alternative measure of peer delinquency based on the logic that follows.

Like many other criminologists who study the relationship between delinquency and delinquent peers, Beaver and colleagues used an indirect measure of peer delinquency constructed by asking respondents about the delinquent behaviors of their close friends. However, literature suggests that adolescents tend to project their own behavior when asked to report their friends' behavior, a phenomenon often referred to as "assumed similarity" (Jussim \& Osgood, 1989). When reporting their friends' delinquency, respondents may impute their own delinquent qualities to their friends, thereby overstating the strength and magnitude of the association between delinquency and delinquent peers (Gottfredson \& Hirschi, 1990; Haynie, 2001).

By the same token, it might be possible that the association between one's genotype and befriending actual delinquent peers revealed in Beaver et al. (2008) was also influenced by the projection of their own behaviors and attitudes, which are derived from their genetic predispositions. That is, as long as perceived peer delinquency is used as a phenotype of interest, questions remain regarding whether such a measure provides accurate portraits of peer delinquency or is more likely to be influenced by perceptions, irrespective of peers' actual behavior (Button et al., 2009). Thus, it appears a worthwhile endeavor to replicate Beaver et al.'s study by employing an objective/direct measure of peer delinquency instead of perceived/indirect peer delinquency.

Our goal in this study is rather narrow: it is to ascertain whether the robust association between genetic polymorphisms and befriending delinquent peers found in Beaver et al. (2008) can be replicated using a direct measure of peer delinquency. Taking advantage of the "peer network approach" (Haynie, 2001), we adopt a measure of peer delinquency constructed from the accounts of respondents' friends on their own delinquent involvement. By using such a measure, it becomes possible to capture the nature of the relationship between genetic polymorphisms and befriending delinquents in a possibly more conservative 
This is an author-produced, peer-reviewed version of this article. The final, definitive version of this document can be found online at Youth Violence and Juvenile Justice, published by SAGE. Copyright restrictions may apply. DOI: 10.1177/1541204010388527

manner. If our analyses yield similar results as Beaver et al.'s, then the confidence in the role of genotype on self-selection of delinquent peers can be strengthened. ${ }^{1}$

\section{Research on Delinquent Peers and the Peer Network Approach}

The literature on the relationship between delinquency and delinquent peers consistently shows that the predictive power of peer delinquency surpasses that of other known correlates of delinquency (Agnew, 1991; Akers, 1998; Matsueda \& Anderson, 1998; Warr, 2002). However, the literature also reveals a lack of clarity in conceptualizing peer delinquency. That is, most previous research has utilized an indirect measure of peer delinquency obtained by asking respondents how many of their close friends have engaged in particular delinquent acts. In other words, peer delinquency was construed from the respondents' perceptions of their peers' delinquency rather than directly from the peers themselves.

This practice is based on the assumption that the respondents' perception of their friends' attitudes and behaviors accurately reflect the friends' attitudes and behaviors. However, the veracity of such assumption has yet to be tested. Rather, it is more than likely that respondents misrepresent friends' behaviors by projecting their own delinquent qualities to those whom they consider their close friends. Indeed, research has shown that people have a strong tendency to project their own attributes to others (Haynie, 2001; 2002; Kandel \& Davies, 1991; Jussim \& Osgood, 1989). To the extent that this is true, the strong delinquencypeer association that is consistently found may have been overstated owing to the self-report measure. Based on this logic, Gottfredson \& Hirschi long ago stated that the conventional measure of peer delinquency "may merely be another measure of self-reported delinquency" (1991, p. 157).

Against this backdrop, particularly noteworthy are Haynie's $(2001$; 2002) recent pieces, in which peer delinquency was measured directly from the friends' responses on their own delinquent involvement rather than relying on respondents' perceptions. Haynie was able to use such an objective measure of peer delinquency due to the peer network data available from the National Longitudinal Study on Adolescent Health (Add Health hereafter). The Add Health network data (Udry, 1998; 2003) relies on a peer network approach and is generated first by asking respondents both to describe their own delinquent behaviors and to identify their close friends. The process then involves locating and interviewing the friends and asking them to report their own involvement in delinquency and then identifying their friends, and so on. The data, thus, allow a rare opportunity where links among friends are constructed for the purpose of forming analytical peer networks. Through the peer networks, the Add Health project produces a direct measure of peer delinquency, which is a delinquency count of both those who the respondent nominated as friends and those who nominated the respondent as friends.

Using this direct measure of peer delinquency, Haynie's (2001) regression models show the effects of delinquent peers (although remaining statistically significant) on respondents' delinquency were attenuated (see also Cleveland, Wiebe, \& Rowe, 2005). These findings should motivate researchers to question the legitimacy of using the indirect measure of peer delinquency as opposed to the measure based on the peer network approach.

\section{Prior Research on Genetic Effects on Delinquent Peer Association}

Although delinquent peer association has long been underscored as a primary correlate of delinquency, relatively little attention has been paid to the question "what in fact causes delinquent peer association?" Criminologists that have examined the issue focused primarily on the role of family-environmental variables, such as direct and indirect role of parents (Harris, 1998; Hirschi, 1969) or proximity to delinquent peers (Warr, 2002). The possibility that genes may underlie the propensity to befriend

\footnotetext{
${ }^{1}$ As one of the reviewers points out, when testing a self-selection thesis, perceived peer delinquency can be a more suitable measure than measures of objective peer delinquency because if a delinquent adolescent opts to befriend other delinquents, then what matters is that they think that the other adolescents are delinquent. Whether they are actual delinquents or not does not matter (see also Button et al., 2009; Hoffmann \& Dufur, 2008). While acknowledging the plausibility of this logic, we emphasize that the focus of the current study is to examine whether genes influence delinquents to associate with other adolescents who are in fact delinquents, taking into account the possibility that some of the variance in delinquent peer association can be caused by associating with adolescents who are perceived as delinquent but in fact are not delinquents.
} 
This is an author-produced, peer-reviewed version of this article. The final, definitive version of this document can be found online at Youth Violence and Juvenile Justice, published by SAGE. Copyright restrictions may apply. DOI: 10.1177/1541204010388527

delinquents has never been empirically examined by mainstream criminologists until recently. However, there are several studies that specifically examined genetic underpinnings of delinquent peer association (Beaver et al., 2008; Cleveland et al., 2005; Iervolino et al., 2002; Kendler et al., 2007).

The latter three studies used a behavioral-genetic design in which variance in the outcome variable is decomposed into genetic effects, shared environments, and non-shared environments components. Iervolino et al. (2002) investigated the respective proportion of variance in peer delinquency utilizing two different samples of adolescent siblings from two different study projects. The measure of peer delinquency included items that tapped rebelliousness, drug-taking behavior, and unconformity, all of which were measured by respondents' reports on peers, thus presenting the potential problem of of assumed similarity. The results of this study were inconsistent, with one sample indicating chiefly environmental influences on peer delinquency and the other indicating largely genetic influences.

Cleveland et al. (2005) employed a direct and more rigorous measure of peer delinquency, taking advantage of the Add Health's peer network data. Although direct, their measure of peer delinquency was limited in that it tapped only tobacco smoking and alcohol drinking. In this study, they found significant genetic underpinnings of delinquent peer affiliation, where genetic factors accounted for as much as $64 \%$ of its variance. In a more recent study of $756 \mathrm{MZ}$ and DZ twin pairs, Kendler et al. (2007) revealed a slightly different picture in which the majority of variance was accounted for by non-shared environments while genetic factors accounted for only $30-50 \%$. Peer delinquency was measured indirectly in this study by asking the respondents how many of their friends engaged in five different delinquent acts.

These three studies indicated some genetic influences on delinquent peer association, thereby suggesting an existence of active gene-environment correlation (rGE). However, behavior genetic studies such as these only show that genes are involved; they cannot say which genes. To this goal, molecular genetic studies such as the study of Beaver et al. (2008) are particularly important. In this study it was shown that a particular variant of the dopamine transporter gene (DAT1), the 10-repeat (10R) allele, is associated with the tendency to befriend delinquent adolescents. Beaver and colleagues used genetic data $(N=1,816)$ from the Add Health study which includes measures of five genetic polymorphisms. Their analyses reveal a clear and consistent pattern in which the DAT1 polymorphism, among others, significantly predicts associating with delinquent peers among male adolescents controlling for age, one's own delinquency, low self-control, drug and alcohol use, and having a criminal father. In addition to exhibiting an active rGE, this study also demonstrates a process of the GxE, which the authors themselves somehow failed to elaborate. Specifically, the significant effect of the DAT1 polymorphism was present only among male adolescents from high-risk family environments marked by a disengaged mother and an absence of maternal affection. Such genetic effect was not found among adolescents from low-risk families.

In short, Beaver et al.'s (2008) study demonstrates the co-occurrence of rGE and GxE; i.e., adolescents self-select themselves into the delinquent peer environment on the basis of their genetic preferences (rGE), while at the same time the genetic effect of self-selection into the delinquent peer network is moderated by the family environment (GxE). Thus, Beaver et al.'s (2008) clearly supports previous behavioral-genetic design studies on delinquent peer formation. It also suggests the inadequacy of traditional criminologists' propositions that the phenomenon of delinquent peer formation can be attributed mainly to familyenvironmental factors.

Similar to most prior studies, Beaver and colleagues employed an indirect measure of peer delinquency by asking respondents how many of their three closest friends smoked cigarette, drank alcohol, and smoked marijuana. In light of the argument presented earlier in regard to assumed similarity (Gottfredson \& Hirschi, 1990; Haynie, 2001; Jussim \& Osgood, 1989), it is suspected that the consistent effect of the DAT1 polymorphism on delinquent peer association discovered in their study may also have been influenced by respondents' perceptions that can be affected genetically. In this regard, an attempt to replicate their findings using an alternative measure not affected by perception may turn out fruitful. Such an effort seems in line with the research tradition of triangulation, an attempt to increase the overall validity of study findings by using different methods (Tashakkori \& Teddlie, 1998). Pertinent examples are amply found in behavioral genetics and developmental psychology research. For instance, with regard to studies on children's genetic effects on family environments, initial studies frequently uncovered genetic effects when 
This is an author-produced, peer-reviewed version of this article. The final, definitive version of this document can be found online at Youth Violence and Juvenile Justice, published by SAGE. Copyright restrictions may apply. DOI: 10.1177/1541204010388527

children's self-reported perceptions of family environments were utilized as phenotypes (Hur \& Bouchard, 1995; Plomin et al., 1989; Rowe, 1983). In order to rule out the potential confound due to genetically influenced perceptions, more recent studies employed alternative sources such as parents' reports or independent observers' reports (Ge, Conger, Cadoret, \& Neiderhiser, 1996; O’Connor, Hetherington, Reiss, \& Plomin, 1995; Rende et al., 1992), subsequently revealing similar genetic effects. These findings offer rather convincing evidence of genetic effects because they are obtained after eliminating children's genetically linked perceptual biases. In all, the convergence of findings based on different methods bolsters genetic effects on family environments.

In a similar vein, we replicate Beaver et al.'s (2008) employing an alternative measure of peer delinquency by taking advantage of the peer network approach, which directly measures peer delinquency from the accounts of friends themselves. We also add to Beaver et al. by utilizing a more diverse set of delinquency items available in the peer network data of the Add Health. These items go beyond the single substance use dimension of delinquency in the Beaver et al. (2008) study. As with the aforementioned triangulation example in family environment studies, if our study turns out producing similar results as Beaver et al.'s, one can have more confidence in the genetic effects on delinquent peer association.

\section{DAT1, Antisocial Behavior, and Delinquent Peer Association}

DAT1 is a gene that regulates the level and duration of dopamine receptor activation.

The neurotransmitter dopamine is a powerful regulator of reward behavior and cognitive functions. When a reduction in dopaminergic functioning occurs, behavioral and cognitive dysregulation typically ensues, leading individuals to seek out pleasures, legal or illegal, to elevate dopamine to an optimum level (Guo, Roettger, \& Shih, 2007; Mill et al., 2002).

The DAT1 gene contains $6,7,8,9,10$, and 11 repeat alleles. The $10 \mathrm{R}$ allele is associated with reduced dopminergic functioning, since it facilitates more efficient reuptake of dopamine in the synaptic cleft than other repeats (Mill et al., 2002). Studies that have looked at the association between the DAT1-10R allele and various forms of antisocial outcomes generally find it to be a risk allele. For instance, Beaver, Wright, $\&$ Walsh (2008) found that it was significantly related to antisocial behavior among a sample of 2,574 males between the ages of 18 and 26. It is also found to be associated with ADHD and conduct disorder (Rowe et al., 2001), pathological gambling (Comings et al., 2001), and other externalizing behaviors (Guo et al., 2007; Young et al., 2002). Only the Beaver et al (2008) study examined the potential effect of DAT1-10R on befriending delinquent peers, but the volume of research attesting to the association between it and antisocial behaviors also hints at this gene's possible influence on delinquent peer affiliation.

\section{Methodology}

\section{Sample}

Previous studies have rarely used a direct measure of peer delinquency partly because the requisite data based on peer networks have not been readily available. The sample for the current study is extracted from the restricted-use data of Add Health (Udry, 1998; 2003). Known as the largest, most comprehensive longitudinal survey of adolescents, the first wave of Add Health data was collected in 1994-1995 from adolescents in grades 7 through 12. At Wave I, both In-School interviews and In-Home interviews were conducted. With a relatively low attrition rate, wave II data were collected in 1996, while Wave III data were collected in 2001-2002, when the initial participating adolescents reached the young adult stage.

Going considerably beyond other nationally representative surveys of adolescent delinquency, the first wave of Add Health study collected friendship network data for students in 132 randomly selected schools. Every student attending the schools on the day that an in-school survey was conducted $(\mathrm{N}=75,871)$ was asked to provide information on their own participation in six minor forms of delinquent activities. In addition, they were asked to nominate up to five closest male friends and five closest female friends from a school roster. Since friendship nominations were recorded by student identification number from school rosters, very detailed social network data were obtained whereby most of the students in the schools were 
linked together. Making use of this detailed network information, the mean delinquency rate of each respondent's peer network was calculated. ${ }^{2}$ In so doing, the Add Health data allow a more accurate conceptualization of friendship networks as well as a more rigorous measure of peer delinquency than the conventional measure of peer delinquency.

At Wave III, saliva samples were collected from a subset of the original sample to genotype DNA for five candidate polymorphisms: the dopamine transporter (DAT1), the dopamine D4 receptor (DRD4), the serotonin transporter (5HTT), monoamine oxidase A (MAOA), and the dopamine D2 receptor (DRD2) (Udry, 2003). The genetic subsample consists of 2,574 monozygotic twins (11\%), dizygotic twins (18\%), and siblings $(70 \%)$. The inclusion of genetic measures along with the direct measure of peer delinquency based on friendship networks in Wave III provides a rare opportunity to examine the research question of this study.

The sample for this study is restricted to the DNA subsample for which the direct measure of peer delinquency can be constructed through the friendship networks. Because MZ twins are genetically identical, including both MZ twins in the genetic analysis would essentially result in double counting them from a genetic perspective. For this reason, we randomly eliminated one twin from each MZ twin pair from the analyses. This technique has frequently been adopted by researchers who analyzed the DNA sample of Add Health (Beaver et al., 2008; Haberstick et al., 2005).

In the case of DAT1 variable, we dropped 7 cases which had a missing value on either of the two alleles. We also dropped two more cases which were judged as overly influential after conducting multiple diagnostic procedures. Adolescents whose complete network data were unobtainable were further dropped from analyses. Our final analytical sample consists of 1,653 respondents whose both genetic and friendship network information is available. The final sample consists of 797 males and 856 females with a mean age of $16(\mathrm{SD}=1.63)$.

\section{Measures}

Direct Peer Delinquency. To avoid this problem of projection or the influence of assumed similarity, a direct measure of peer delinquency is used. In order to construct this measure, adolescents reported their involvement in six minor delinquent acts during the past 12 months, including smoking cigarettes, drinking alcohol, getting drunk, racing on a bike or car, having been in danger due to dare, and having skipped school without an excuse (see Appendix 1 to see the description of the items) at Wave I In-School interviews.

Taking advantage of the peer network data, first, the mean delinquency for each item in a respondent's peer network was calculated. The formula for the mean peer delinquency for each item is MEAN $x=\sum x_{\mathrm{j}} / \mathrm{n}_{\mathrm{j}}$, where $\mathrm{x}=$ each delinquency item, $x_{j}$ is the value of $x$ for the $j$ th member of the peer network, and $n_{j}$ is the number of nodes in the peer network with valid data on $x$ (for a detailed explanation, see Haynie (2001)). Then, in order to create the peer delinquency index, we summated the means for the six peer delinquency items (alpha=.75). This index is a direct measure of peer delinquency, which represents the average level of delinquent involvement of the respondent's closest friends.

Indirect Peer Delinquency. The indirect peer delinquency is what Beaver et al. used as the dependent variable. Adolescents reported at Wave 1 In-home interviews how many of their three closest friends engaged in the following three delinquent acts: smoking cigarette, drinking alcohol, and smoking pot. The sum of the responses to the three items forms the measure of indirect peer delinquency (alpha=.76).

\footnotetext{
${ }^{2}$ Respondents were allowed to nominate out-of-school friends (e.g., drop-outs). However, because the friendship network data rely on respondents' school rosters, the data do not include detailed information on such out-of-school friends. Nonetheless, the number of outside nominations averaged only 1.4 ties per adolescent. Besides, out-of-school nominations do not statistically differ between delinquents and non-delinquents (see Haynie, 2001).
} 
Dopamine Transporter Gene (DAT1). The DAT1 gene has been mapped to chromosome 5 at location 5p15.3 (Vandenbergh et al., 1992). It has a 40-base variable number of tandem repeats (VNTR) that can be repeated 3-11 times. The most common polymorphisms accounting for over 90 percent of all alleles of the DAT1 in Caucasians and the African Americans are the 9-repeat (9R) and the 10-repeat (10R) alleles (Doucette-Stamm et al., 1995). With the Add Health sample, over 96\% had one of the following combinations of alleles: (1) two 10R alleles, (2), two 9R alleles, or (3) one 10R allele and one 9R allele. In line with previous studies, thus, adolescents who had an allele other than a $10 \mathrm{R}$ and a $9 \mathrm{R}$ were removed from analyses (Beaver et al., 2008; Hopfer et al., 2005). Given that the 10R allele is considered the risk allele, the allele combinations are recoded and given the values of 0,1 , or 2 to reflect the presence of zero, one, or two 10R alleles. Among the 1,653 adolescents, 5.4\% are 9R/9R homozygotes, 34.5\% are 9R/10R heterozygotes, and $60 \%$ are $10 \mathrm{R} / 10 \mathrm{R}$ homozygotes. Hardy-Weinberg equilibrium was fulfilled, $X^{2}(1$, $N=1,653)=.0025, p>.05$.

Family Risk. Parental control and support for their adolescents have consistently been found to be associated with adolescents' delinquent peer association (Wright \& Cullen, 2001). We constructed a global measure of maternal control and support that integrates three closely related constructs measured at Wave 1In-home Interview. First, maternal attachment was measured by two items that asses how closely the mother and her adolescent are emotionally attached to each other. Specifically, respondents were asked about how close they felt to their mother and how much they thought their mother cared about them. Secondly, maternal involvement was captured via eight items that measured the extent to which mothers engaged in activities with their child in the past four weeks. The eight items include playing a sport; going to a movie, play, or sporting event; talking about a dating partner, a personal problem, and things at school; and working on a project for school. ${ }^{3}$ Finally, maternal disengagement was measured by five items tapping how cold and withdrawn the adolescent perceived their mother to be.

All the fifteen items constituting these constructs were recoded in a way that higher scores represented more maternal disengagement and less attachment. The items demonstrated a high internal consistency (alpha=.79) and, when factor analyzed, loaded on a single factor. Following Beaver et al. (2008), regression factor scores are used to reflect family risk. We dichotomized the family risk factor scores by splitting at the mean, assigning the value of 0 to scores below or equal to the mean and 1 to scores above the mean. Adolescents with a score below 1 were regarded living in low-risk families, while those with the score of 1 living in high-risk families.

Control variables. Following Beaver et al. (2008), we included five control variables garnered from Wave I In-home data collection to help reduce model misspecification and to control for potential confounders. First, respondents' age at Wave 1 was included as a potential confounding factor. As children move into adolescence, the salience of peer relationship increases, and time spent in the company of peers overtakes time spent with parents (Gottfredson \& Hirschi, 1990; Warr, 1993). Also a measure tapping whether a respondent's biological father ever served time in jail or prison was also included. Because the genetic predisposition of a criminal father can be transmitted to his offspring (Moffitt, 2005; Wright \& Beaver, 2005), thereby potentially increasing offspring's risk for affiliation with antisocial peers, including this measure can partially control for passive rGEs. The variable, Criminal Father, is a dichotomous variable measured at Wave 3.

Prior research indicates that one of the strongest correlates of delinquent peer affiliation is one's own delinquent involvement (Gottfredson \& Hirschi, 1990; Hawkins, Catalano, \& Miller, 1992). To control for the confounding effect of one's own delinquency, therefore, we used an additive index of self-reported delinquent involvement measured at Wave 1. The self-reported delinquency index consists of 14 different items, which tap a variety of delinquent behaviors adolescents engaged in during the past year. These behaviors range from minor delinquency such as painting graffiti, vandalism, shoplifting, burglarizing, and joyriding to more serious or violent behaviors such as drug selling, serious physical fight, gang fight, wielding weapons, stabbing, and gun shooting. Each response to the 14 items is coded "1" if the respondent

\footnotetext{
${ }^{3}$ Beaver et al. (2008) originally used ten items to measure maternal involvement. Two items (going to a religious service and having had a serious argument) were dropped in our analysis due to a reduction in Cronbach's alpha.
} 
This is an author-produced, peer-reviewed version of this article. The final, definitive version of this document can be found online at Youth Violence and Juvenile Justice, published by SAGE. Copyright restrictions may apply. DOI: 10.1177/1541204010388527

reported participating more than once during the past year and "0" if the respondent did not report participating. Responses to these items were summated to form the self-report delinquency index (alpha=.80).

Gottfredson \& Hirschi (1990) maintain that individuals with low self-control tend to end up in the company of peers who are also low in self-control. Prior researchers analyzing the Add Health data utilized five items to measure low self-control (Beaver et al., 2008; Perrone, Sullivan, Pratt, \& Margaryan, 2004). Specifically, adolescents at Wave 1 were queried whether they had trouble getting along with their teachers, trouble paying attention, trouble keeping their mind focused, and trouble finishing their homework. Also asked was whether they felt that they did everything just right. The responses to the five items are summated to form the low self-control scale (alpha=.69). Lastly, research suggests a strong link between substance abuse and delinquent peer affiliation (Iervolino et al., 2002). To measure the degree to which adolescents are involved in drug and alcohol use, two items at Wave I data collection were used. First, adolescents were asked how frequently they had consumed alcohol in the past 12 months with an answer category ranging from 1 (every day) to 7 (never), which was recoded in a way that higher score denotes more frequent alcohol consumption. The other item pertains to how many days adolescents had smoked marijuana in the past month. We summed these two items to form the drug and alcohol index.

\section{Plan of Analysis}

Our analytical procedures primarily follow Beaver et al.'s (2008) and begin with an examination of Pearson correlations among key variables, followed by estimating a series of ordinary least squares regression models.

At the first phase of regression estimation, two different measures of peer delinquency-direct and indirect - are regressed on three predictor variables. This is done to ascertain whether the magnitude of rGE between DAT1-10R and delinquent peer affiliation is influenced by the type of peer delinquency measured. Next, to test for G× E interactions, we calculated split-sample models using family risk as a split criterion. Split-sample models have been often used by researchers to assess interactions between biological and environmental factors (Beaver et al., 2008; Turner, Hartman, \& Bishop, 2007). If the coefficient for high family risk sample was different from the coefficient for low family risk sample, then a GxE interaction would be detected. Therefore, one could reasonably conclude that the association between DAT1 and befriending antisocial peers would be contingent upon differential exposures to family environment. ${ }^{4}$

The amount of missing data was less than $5 \%$ for all of the individual study variables. To avoid selection bias and inaccurate inferences resulting from listwise deletion, we imputed variables with missing values using regression method. To assess the effect of imputation on our results, we ran all of our multivariate analyses with both imputed and non-imputed variables and found no substantial difference in the results. For simplicity, we present only the results using imputed variables.

\section{Results}

Beaver et al.'s (2008) study reported that the 10R allele of the dopamine transporter (DAT1) gene was significantly associated with male respondents' self-reported peer delinquency among both white and black male adolescents from high-risk families.

***Insert Table 1 about Here***

\footnotetext{
${ }^{4}$ Using the split-sample method, however, can substantially reduce statistical power because of the relative small sample sizes of black males (89 and 56, respectively). Thus, we calculated additional regression equations by incorporating a multiplicative interaction term of DAT1 and Family risk, instead of splitting the sample. Because the results of the analyses are basically the same as the results of the split-sample method, we present the results of the additional analyses in Appendix 2.
} 
As shown in Table 1, we first examined the magnitude of Pearson correlations among the key variables. We see that the 10R allele of DAT1 gene is not significantly associated with either the direct or indirect measure of friends' delinquency. It would be, however, hasty to conclude that this genetic polymorphism has no effect at all on befriending delinquent peers because, as Beaver et al. (2008) indicate, the genetic expression of the DAT1-10R allele occurs only under specific circumstances, such as among males from high-risk family environment.

Also importantly, the correlation between the two measures of peer delinquency-direct and indirect-is only .45 . This modest correlation between the two measures that supposedly measure the same construct illuminates the fact that the level of peer delinquency based on respondents' self-report is to a degree dissimilar to the level of peer delinquency that was directly measured.

$$
\text { ***Insert Table } 2 \text { about Here*** }
$$

Next, we regressed the two measures of friends' delinquency on DAT1, age, and criminal father for the full sample and separately by gender (see Table 2). Across all of the six models, age was the most consistent and robust predictor of befriending antisocial friends ( $\beta$ range $=.15-.28)$. DAT1 exerted a statistically significant and positive effect on friends' delinquency for male adolescents, but not for female adolescents. The effect for males was observed only for the indirect measure of friends' delinquency model. When the direct measure of peer delinquency was regressed, the regression coefficient for DAT1 failed to reach the conventional .05 significance level. This finding is in line with our argument that using respondents' reports of peer delinquency rather than peers' self-reported delinquency will overestimate the correlation between genetic polymorphisms and associating with antisocial friends.

We then examined the phenomenon of GxE interactions using family risk as the split criterion, using only the direct measure of peer delinquency as the dependent variable. Adolescents who received a score lower than the mean of the family risk scale are categorized as low family risk adolescents, while adolescents who received a score higher than the mean are classified as high family risk. If a GxE exists, then the risk allele of DAT1 could be phenotypically expressed only among adolescents from high risk families, but not among those from low risk families. Or the magnitude of the coefficient for the risk allele among the high risk adolescents would be substantially greater than that among the low risk adolescents. In other words, the effect of DAT1 will be moderated by different levels of family risk. We estimated regression models only for males because none of the female models in Table 2 exhibited statistically meaningful results for the DAT1 variable. Because the allelic combinations of certain genetic polymorphism vary across racial and ethnicity lines (Sarich \& Miele, 2004; Shields et al., 2005), we estimated separate models for Blacks and Whites.

\section{***Insert Table 3 about Here***}

Table 3 presents the regression results for the low- and high-risk family groups for the full male adolescents and for white and black male adolescents separately. Among all the predictors in the low-risk family models, age is the only significant predictor of affiliating with delinquent peers: DAT1 does not exhibit any statistically meaningful effect in any of the models. In the high-risk family models, DAT1 emerges as a significant predictor, although the effect is limited to white adolescents only. This result clearly substantiates a GxE where the effect of the risk allele is contingent on environmental influences, without which the effect of the genetic polymorphism is mute. ${ }^{5}$

$$
\text { ***Insert Table } 4 \text { about Here*** }
$$

\footnotetext{
${ }^{5}$ Following Beaver et al.'s analytical process, we controlled for criminal father in the models in Table 3 . Yet, as one reviewer points out, it is possible that the association between DAT1 and delinquent peer association can be mediated by criminal father. In order to test such statistical mediation, we ran all the models in Table 3 first without criminal father and then re-ran including it. If a significant association between DAT1 and peer association in the first model is substantially reduced in the second model, then the mediating role of criminal father could be said to exist (Baron \& Kenny, 1986). However, the results exhibited no such mediation by criminal father.
} 
In the final stage of analyses we investigated whether the positive effect of DAT1 on delinquent peer affiliation among white males from high risk families was an artifact stemming from omission of important variables (see Table 4). To establish ceteris paribus conditions, three potentially confounding variablesdelinquency, low self-control, and drug/alcohol use-measured at Wave 1 were sequentially controlled for in Model 1, 2, and 3. In addition, controls for all of the three variables simultaneously were entered in Model 4. All of the models were estimated using the high-risk white males only ( $\mathrm{N}=245)$. As Table 4 shows, the three control variables strongly and positively predict affiliation with delinquent friends when entered individually, and DAT1 consistently displays statistical significance in all of the models. Further, note that beta coefficients for the three controls are substantially reduced in Model 4, indicating overlapping influences among them on delinquent peer association. However, the beta coefficients for DAT1 barely change despite the inclusion of the controls, indicating independent and unique effects of the genetic polymorphism on delinquent peer association. ${ }^{6}$

\section{Discussion and Conclusion}

The current study sought to replicate Beaver et al.'s (2008) study that demonstrated genetic effects on homophily for delinquency among male adolescents. Being the first research that detected an rGE between a measured genetic polymorphism and delinquent peer affiliation, it certainly warrants a replication given the gravity and potentially far-reaching implications of their findings. Particularly, we attempted to control for the fact that part of the variance in delinquent peer association in Beaver et al.'s study might have been accounted for by adolescents' perceptions. . We addressed this issue by using direct reports of respondents' peers themselves on their own delinquent involvement, taking advantage of the peer network data available in the Add Health.

The findings of our analyses support the results by Beaver et al.'s research except for the fact that an rGE among black male adolescents in the original study disappeared. Yet, when looking at white male adolescents only, the degrees of similarity in results are rather striking. An rGE pattern is distinctively observed despite the inclusion of various controls that are considered consequential by mainstream criminologists. The constant magnitude of the coefficient for DAT1, irrespective of the sequential inclusion of controls, further denotes independent and unique genetic influences on the tendency to befriend delinquents. In line with Beaver et al.'s findings on GxE, the rGE between DAT1 and delinquent peers is present only among those from high risk families. In short, our study reaffirms that genetic predisposition prompts adolescents to self-select themselves into delinquent peer networks (active rGE), and this effect on self-selection is conditioned by family environment (GxE). These results are produced even with the use of an alternative measure of peer delinquency that rules out the influences of assumed similarity. Consequently, our study in tandem with Beaver et al.'s provide a strong support that there exists a consistent link between DAT1 and delinquent peer group formation. That is, delinquent peer formation is the result of an arrangement of genetic and environmental factors working independently and interactively.

One might reasonably ask why then the rGE among black males from high-risk families found in Beaver et al.'s (2008) study disappeared in our analyses. It is suspected that the smaller sample size of high-risk black males $(n=56)$ has contributed to a reduced statistical power. This appears particularly plausible given the beta weights for whites and blacks, which are not quite dissimilar (.15 and .12, respectively). Also, as Hindelang, Hirschi \& Weis's (1981) study suggests, black adolescents in our sample might have reported their delinquency involvement less truthfully than their white counterparts. Another possible reason is that the Add Health sampling design purposely over-sampled black adolescents from families with high educational attainment (Udry, 1998). Thus the variation in family risk in black families may have been

\footnotetext{
${ }^{6}$ Although self-reported delinquency, low self-control, and drug/alcohol abuse are used as controls in our analyses, they can also be conceived as indexes of individual characteristics that contribute to self-selection of and selection by delinquent peers. Yet, the results of our analyses in Table 4 do not substantiate such a mediation hypothesis. In search for potential mediating variables, we calculated two additional regression equations including, first, sensation seeking and, second, impulsivity. Sensation seeking was reflected by four different variables (not using birth control ever, sexual promiscuity, not wearing seat belt in a car, and not wearing helmet riding a bicycle). Impulsivity was measured by summing five items including 'when making decisions, I usually go with gut feeling.' The two auxiliary analyses resulted in basically the same results as in Table 4, suggesting no mediating roles of sensation seeking and impulsivity.
} 
This is an author-produced, peer-reviewed version of this article. The final, definitive version of this document can be found online at Youth Violence and Juvenile Justice, published by SAGE. Copyright restrictions may apply. DOI: 10.1177/1541204010388527

smaller than that among white families. Indeed, the mean on the family risk scale for high-risk white males was $6.78(\mathrm{SD}=3.49)$, while that for high-risk black males was only $4.79(\mathrm{SD}=2.92)$.

Nevertheless, our study adds to the emerging realization in criminology that a wide array of correlates of delinquency has genetic underpinnings. Research from other disciplines, such as behavioral genetics and developmental psychology, has already established that adolescents' behaviors are not severed from their genetic makeup (Button et al., 2009; Cleveland et al., 2005; Guo et al., 2008; Iervolino et al., 2002; Moffitt 2005; Plomin et al., 1977). Thus, it is highly advisable that criminologists and students of criminology begin to incorporate such well-established scientific evidence into their own criminological paradigm (Wright et al., 2008). If they continue to adhere exclusively to the sociological framework as a necessary and sufficient tool in explaining antisocial behaviors, the field of criminology will certainly take a back seat to other disciplines. Evidence in support of the fact that individuals' genotypes are partially responsible for shaping, structuring, and selecting environments is now too compelling to be ignored. Choosing to look the other way amounts to burying criminologists' heads in the sand.

Our study also supports that to improve our understanding of complex human behaviors geneticallyinformed theory and data are required. Given our results and other genetically-informed studies, a promising course of action for future criminologists may be to re-examine each putative sociological predictors of crime and delinquency applying explicit controls for genetic effects. Fortunately, genetic data sets, such as Add Health, are now available which allows criminologists to pursue such a course of action.

We accentuate the fact that research incorporating genetic factors does not negate the policy implications of sociological studies. To the contrary, they frequently reinforce support for policy implications of mainstream criminology research. Note, for example, that our study corroborates the importance of maternal bonding as an element of social control, which has been continuously emphasized by mainstream criminologists (Gottfredson \& Hirschi, 1990; Hirschi, 1969). Moreover, it extends the sociological theory by adding a genetic explanation on why maternal bonding is important: namely, it becomes important because it overrides the adverse effects of the DAT1-10R risk allele. ${ }^{7}$

On a final note, we present implications for future research while recognizing shortcomings of this study. Although more diverse than Beaver et al.'s (2008), our peer delinquency items only tapped minor delinquent acts. A measure incorporating serious and violent delinquent acts would be more desirable in future endeavors and should generate stronger results. Secondly, while our study highlights the interplay between genes and social contexts, it does not address social contexts other than maternal bonding that might alter gene expression. We also recognize that the link between genotype and phenotype is complex, involving gene $x$ gene interactions as well as GxE. Future research should incorporate other genes such as the serotonin transporter gene (5-HTTLPR), the DRD4 receptor gene, and the MAOA enzyme.

\footnotetext{
${ }^{7}$ The role maternal affection and engagement plays appears to be particularly critical in guiding adolescents away from befriending delinquents, especially when one takes into account the distribution of the 10R risk allele in the sample: $60 \%$ of the sample carried two $10 \mathrm{R}$ alleles and $34.5 \%$ at least one $10 \mathrm{R}$ allele. Thus, it seems more reasonable to consider the $9 \mathrm{R}$ allele a "conservative" allele (Guo et al., 2008).
} 


\section{Acknowledgements}

This research used data from Add Health, a program project designed by J. Richard Udry, Peter S. Bearman, and Kathleen Mullan Harris, and funded by Grant P01-HD31921 from the National Institute of Child Health and Human Development, with cooperative funding from seventeen other agencies. Special acknowledgment is due Ronald R. Rindfuss and Barbara Entwisle for assistance in the original design. Persons interested in obtaining data files from Add Health should contact Add Health, Carolina Population Center, 123 West Franklin Street, Chapel Hill, North Carolina 27516-2524 (addhealth@unc.edu). An earlier version of this manuscript was presented at the 2006 annual meeting of the American Society of Criminology in Los Angeles. 


\section{References}

Agnew, R. (1991). The interactive effects of peer variables on delinquency. Criminology, 29(1), 47-72.

Akers, R. (1998). Social learning and social structure: A general theory of crime and deviance. Boston: Northeastern University Press.

Baron, R., \& Kenny, D. (1986). The moderator-mediator variable distinction in social psychological research: Conceptual, strategic, and statistical considerations. Journal of Personality and Social Psychology, 51, 1173-1182.

Beaver, K., DeLisi, M., Vaughn, M., \& Barnes, J. (2009). MAOA genotype is associated with gang membership and weapon use." Comprehensive Psychiatry, 51(2), 130-134.

Beaver, K., Wright, J., \& DeLisi, M. (2008). Delinquent peer group formation: Evidence of a gene x environment correlation. The Journal of Genetic Psychology, 169(3), 227-244.

Beaver, K., Wright, J., \& Walsh, A. (2008). A gene-based evolutionary explanation for the association between criminal involvement and number of sex partners.Biodemography and Social Biology, 54, 47-55.

Button, T., Stallings, M., Rhee, S., \& Corely, R. (2009). Perceived peer delinquency and the genetic predisposition for substance dependence vulnerability. Drug and Alcohol Dependence, Measuring delinquent peers, 100, 1-8.

Caspi, A., McClay, J., Moffitt, T. E., Mill, J., Martin, J., Craig, I., Taylor, A., \& Poulton, R. (2002). Role of genotype in the cycle of violence in maltreated children. Science, 297, 851-854.

Cleveland, H., Wiebe, R., \& Rowe, D. (2005). Sources of exposure to smoking and drinking friends among adolescents: A behavioral-genetic evaluation. The Journal of Genetic Psychology, 166, 153-169.

Comings, D., Gade-Andavolu, R., Gonzalez, N., Wu, S., Muhleman, D., Chen, C., et al.(2001). The additive effect of neurotransmitter genes in pathological gambling. Clinical Genetics, 60, 107116.

Cullen, F. (2009). Foreword to A. Walsh \& K. Beaver, Biosocial Criminology: New directions in theory and research. New York: Routledge.

Doucette-Stamm, L., Blakey, D., Tian, J., Mockus, S., \& Mao, J. (1995). Population genetic study of

human dopamine transporter gene (DAT1). Genetic Epidemiology, 12, 303-308.

Faraone, S., Doyle, A., Mick, E., \& Biederman, J. (2001). Meta-analysis of the association between the 7repeat allele of the dopamine D4 receptor gene and attention deficit hyperactivity disorder. The American Journal of Psychiatry, 158, 1052-1057.

Ge, X., Conger, R., Cadoret, R., \& Neiderhiser, J. (1996). The developmental interface between nature and nurture: A mutual influence model of child antisocial behavior and parent behaviors. Developmental Psychology, 32(4), 574-589.

Gottfredson, M., \& and Hirschi, T. (1990). A General Theory of Crime. Stanford, Calif.: Stanford University Press.

Guo, G., Roettger, M., \& Shih, J. (2007). Contributions of the DAT1 and DRD2 genes to serious and

violent delinquency among adolescents and young adults. Human Genetics, 121, 125-136.

Guo, G., Roettger, M., \& Cai, T. (2008). The integration of genetic propensities into social-control models of delinquency and violence among male youths. American Sociological Review, 74, 543-568.

Haberstick, B., Lessem, J., Hopfer, C., Smolen, A., Ehringer, M., Timberlake, D., \& Hewitt, K. (2005). Monoamine oxidase A (MAOA) and antisocial behaviors in the presence of childhood and adolescent maltreatment. American Journal of Medical Genetics, 135B, 59-64.

Hartl, D., \& Jones, E. (2006). Genetics: Analysis of genes and genomes. Sudbury, MA

Haynie, D. (2001). Delinquent peers revisited: Does network structure matter?" American Journal of Sociology, 106(4), 1013-1057.

Haynie, D. (2002). Friendship networks and delinquency: The relative nature of peer delinquency. Journal of Quantitative Criminology, 18(2), 99-134.

Haynie, D. (2005). Reconsidering peers and delinquency: How do peers matter? Social Forces, 84(2), 1109-1130.

Hawkins, J., Catalano, R., \& Miller, J. (1992). Risk and protective factors for alcohol and other drug problems in adolescence and early adulthood: Implications for substance abuse prevention. Psychological Bulletin. 112. 64-105.

Hindelang, M., Hirschi, T., \& Weis, J. (1981). Measuring Delinquency. Beverly Hills, CA: Sage.

Hirschi, T. (1969). Causes of delinquency. Berkeley, CA: University of California. 
This is an author-produced, peer-reviewed version of this article. The final, definitive version of this document can be found online at Youth Violence and Juvenile Justice, published by SAGE. Copyright restrictions may apply. DOI: 10.1177/1541204010388527

Hoffmann, J., \& Dufur, M. (2008). Family and school capital effects on delinquency: Substitutes or complements? Sociological Perspectives, 51(1), 29-62.

Hopfer, C., Timberlake, D., Haberstick, B., Lessem, J., Ehringer, M., Smolen, A., et al. (2005). Genetic influences on quantity of alcohol consumed by adolescents and young adults. Drug and Alcohol Dependence, 78, 187-193.

Jussim, L. \& Osgood, D. (1989). Influence and similarity among friends: An integrated model applied to incarcerated adolescents. Social Psychology Quarterly, 52(2), 98-112.

Kandel, D., \& Davies, M. (1991). Friendship networks, intimacy, and illicit drug use in young adulthood: A comparison of two competing theories. Criminology, 29 (3), 441-70.

Kendler, K., Jacobson, K., Gardner, C., Gillespie, N., Aggen, S., \& Prescott, C. (2007). Creating a social world: A developmental twin study of peer-group deviance. Archives of General Psychiatry, 64, 958-965.

Kotler, M., Manor, I., Sever Y., Eisenberg, J., Cohen, H., Ebstein, R., \& Tyano, S. (2000). Failure to replicate an excess of the long dopamine D4 exon III repeat polymorphism in ADHD in a familybased study. American Journal of Medical Genetics, 96, 278-281.

Matsueda, R., \& Anderson, K. (1998). The dynamics of delinquent peers and delinquent behavior. Criminology, 36, 269-299.

Mill, J., Asherson, P., Browes, C., D’Souza, U., \& Craig, I. (2002). Expression of thedopamine transporter gene is regulated by the 30 UTR VNTR: Evidence from brain and lymphocytes using quantitative RT-PCR. American Journal of Medical Genetics 114(8), 975-979.

Moffitt, T. (2005). The new look of behavioral genetics in developmental psychopathology: Geneenvironment interplay in antisocial behavior. Psychological Bulletin, 131, 533-554.

Perrone, D., Sullivan, C., Pratt, T., \& Margaryan, S. (2004). Parental efficacy, self-control, and delinquency:

A test of a general theory of crime on a nationally representative sample of youth. International Journal

of $\quad$ Offender Therapy and Comparative Criminology, 48, 298-312.

Plomin, R., DeFries, J., \& Loehlin, J. (1977). Genotype-environment interaction and correlation in the analysis of human behavior. Psychological Bulletin, 84, 309-322.

Rowe, D., Stever, C., Chase, D., Sherman, S., Abramowitz, A., \& Waldman, I. D.(2001). Two dopamine genes related to reports of childhood retrospective inattention and conduct disorder symptoms. Molecular Psychiatry, 6, 429-433.

Robinson, M. (2004). Why crime? An integrated systems theory of antisocial behavior. Upper Saddle River, NJ: Pearson Prentice Hall.

Sarich, V., \& Miele, F. (2004). Race: The reality of human differences. Boulder, CO: Westview.

Scarr, S., \& McCartney, K. (1983). How people make their own environments: A theory of genotype $\rightarrow$ environment effects. Child Development, 54, 424-435

Shanahan, M., \& Hofer, S. (2005). Social context in gene-environment interactions: Retrospect and prospect. The Journals of Gerontology Series B: Psychological Sciences and Social Sciences, 60, $65-76$.

Shields, A., Fortun, M., Hammonds, E., King, P., Lerman, C., Rapp, R., \& Sullivan, P. (2005). The use of race variables in genetic studies of complex traits and the goal of reducing health disparities: A transdisciplinary perspective. American Psychologist, 60, 77-103.

Tashakkori, A., and Teddlie, C. (1998). Mixed methodology: Combining qualitative and quantitative approaches. Thousand Oaks, CA: Sage Publications.

Turner, M. G., Hartman, J. L., \& Bishop, D. M. (2007). The effects of prenatal problems,family functioning, and neighborhood disadvantage in predicting life-course-persistent offending. Criminal Justice \& Behavior, 34, 1241-1261.

Udry, J. (1998). The National Longitudinal Sample of Adolescent Health. Chapel Hill: Carolina Population Center, University of North Carolina at Chapel Hill.

Udry, J. R. (2003). The National Longitudinal Study of Adolescent Health (Add Health), Waves I and II, 1994-1996; Wave III, 2001-2002 [machine-readable data file and documentation]. Chapel Hill: Carolina Population Center, University of North Carolina at Chapel Hill.

Vandenbergh, D., Persico, A., Hawkins, A., Griffin, C., Li, X., Jabs, E., \& Uhl, G. (1992). Human dopamine transporter gene (DAT1) maps to chromosome 5p15.3 and displays a VNTR. Genomics, 14, 1104-1106. 
Vaughn, M., Fu, Q., DeLisi, M., Beaver, K., Perron, B., \& Howard, M. (2010). Criminal victimization and comorbid substance use and psychiatric disorders in the United States: Results from the NESARC. Annals of Epidemiology. In press.

Vaske, J., Beaver, K., Wright, J., Boisvert, D., \& Schnupp, R. (2009). An interaction between DAT1 and having an alcoholic father predicts serious alcohol problems in a sample of males. Drug and Alcohol Dependence, 104, 17-22.

Walsh, A. (2002). Essay review. Companions in crime: A biosocial perspective. Human Nature Review, 2, $169-178$.

Walsh, A. (2009). Biology and criminology: The biosocial synthesis. New York : Routledge Research.

Warr, M. (2002). Companions in crime: The social aspects of criminal conduct. Cambridge, England: Cambridge University Press.

Wright, J., \& Cullen, F. (2001). Parental efficacy and delinquent behavior: Do control and support matter? Criminology, 39, 677-706.

Wright, P., Beaver, K., DeLisi, M., Vaughn, M., Boisvert, D., \& Vaske, J. (2008). Lombroso's legacy: The miseducation of criminologists. Journal of Criminal Justice Education, 19(3), 325-338.

Young, S., Smolen, A., Corley, R., Krauter, K., DeFries, J., Crowley, T., et al. (2002). Dopamine transporter polymorphism associated with externalizing behavior problems in children. American Journal of Medical Genetics, 114, 144-149. 
This is an author-produced, peer-reviewed version of this article. The final, definitive version of this document can be found online at Youth Violence and Juvenile Justice, published by SAGE. Copyright restrictions may apply. DOI: 10.1177/1541204010388527

Table 1. Pearson Correlations among Key Variables

\begin{tabular}{|c|c|c|c|c|c|c|}
\hline & DAT1 & $\begin{array}{c}\text { Direct } \\
\text { peer delinquency }\end{array}$ & $\begin{array}{c}\text { Indirect } \\
\text { peer delinquency }\end{array}$ & $\begin{array}{c}\text { Self-reported } \\
\text { delinquency }\end{array}$ & Age & $\begin{array}{c}\text { Family } \\
\text { risk }\end{array}$ \\
\hline DAT1 & 1 & & & & & \\
\hline Direct peer delinquency & -.02 & 1 & & & & \\
\hline Indirect peer delinquency & .02 & $.45^{*}$ & 1 & & & \\
\hline Self-reported delinquency & -.02 & $.21 *$ & $.38^{*}$ & 1 & & \\
\hline Age & $.05^{*}$ & $.17 *$ & $.25^{*}$ & -.04 & 1 & \\
\hline Family risk & $.05^{*}$ & $.11 *$ & $.16^{*}$ & $.13 *$ & $.14 *$ & 1 \\
\hline Criminal father & -.02 & .04 & $.06 *$ & $.07 *$ & -.04 & .01 \\
\hline
\end{tabular}


Table 2. Effects of DAT1 Gene on Two Different Measures of Delinquent Peer Association

\begin{tabular}{|c|c|c|c|c|c|c|c|c|}
\hline \multirow[b]{2}{*}{ Variable } & \multicolumn{4}{|c|}{ Indirect peer delinquency } & \multicolumn{4}{|c|}{ Direct peer delinquency } \\
\hline & $b$ & $S E$ & B & $R^{2}$ & $b$ & $S E$ & $\beta$ & $R^{2}$ \\
\hline Full sample $(n=1,653)$ & & & & .03 & & & & .06 \\
\hline DAT1 & .06 & .1 & .01 & & -.13 & .14 & -.02 & \\
\hline Age & .38 & .04 & $.24^{*}$ & & .35 & .05 & $.17 *$ & \\
\hline Criminal father & .53 & .17 & $.07 *$ & & .2 & .84 & $.05^{*}$ & \\
\hline Male adolescents $(n=797)$ & & & & .08 & & & & .04 \\
\hline DAT1 & .27 & .14 & $.07 *$ & & .08 & .19 & .02 & \\
\hline Age & .43 & .05 & $.28 *$ & & .4 & .07 & $.19 *$ & \\
\hline Criminal father & .26 & .26 & .03 & & .21 & .36 & .02 & \\
\hline Female adolescents $(n=856)$ & & & & .05 & & & & .02 \\
\hline DAT1 & -.15 & .14 & -.03 & & -.31 & .2 & -.05 & \\
\hline Age & .32 & .05 & $.21 *$ & & .29 & .07 & $.15^{*}$ & \\
\hline Criminal father & .75 & .23 & $.11 *$ & & .69 & .31 & $.07 *$ & \\
\hline
\end{tabular}

*Significant at the .05 level, two-tailed. 


\begin{tabular}{|c|c|c|c|c|c|c|c|c|c|c|}
\hline \multirow[b]{2}{*}{ Variable } & \multicolumn{4}{|c|}{ Low-risk family } & \multicolumn{6}{|c|}{ High-risk family } \\
\hline & $b$ & $S E$ & $B$ & $R^{2}$ & $n$ & $b$ & $S E$ & B & $R^{2}$ & $n$ \\
\hline Male adolescents & & & & .07 & 449 & & & & .02 & 348 \\
\hline DAT1 & -.18 & .25 & -.03 & & & .35 & .31 & .06 & & \\
\hline Age & .53 & .09 & $.26^{*}$ & & & .17 & .13 & .07 & & \\
\hline Criminal father & .19 & .48 & -.02 & & & .65 & .56 & .06 & & \\
\hline White males & & & & .12 & 296 & & & & .03 & 245 \\
\hline DAT1 & -.09 & .32 & -.02 & & & .85 & .36 & $.15^{*}$ & & \\
\hline Age & .72 & .11 & $.35^{*}$ & & & .17 & .15 & .07 & & \\
\hline Criminal father & .17 & .63 & .01 & & & .46 & .65 & .05 & & \\
\hline Black males & & & & .02 & 89 & & & & .05 & 56 \\
\hline DAT1 & .11 & .39 & .03 & & & .58 & .68 & .12 & & \\
\hline Age & -.04 & .16 & -.03 & & & -.13 & .24 & -.07 & & \\
\hline Criminal father & .82 & .67 & .12 & & & -2.02 & 1.41 & -.2 & & \\
\hline
\end{tabular}

*Significant at the .05 level, two-tailed.

Table 4. Tests of Association between DAT1 and Delinquent Peers among High-risk White Males with Additional Control Variables $(\mathrm{N}=245)$

\begin{tabular}{|c|c|c|c|c|c|c|c|c|c|c|c|c|}
\hline \multirow[b]{2}{*}{ Variable } & \multicolumn{3}{|c|}{ Model 1} & \multicolumn{3}{|c|}{ Model 2} & \multicolumn{3}{|c|}{ Model 3} & \multicolumn{3}{|c|}{ Model 4} \\
\hline & $b$ & $S E$ & B & $b$ & $S E$ & B & $b$ & $S E$ & B & $b$ & $S E$ & B \\
\hline DAT1 & .86 & .35 & $.15^{*}$ & .78 & .4 & $.14 *$ & .85 & .36 & $.15^{*}$ & .80 & .34 & $.14 *$ \\
\hline
\end{tabular}


This is an author-produced, peer-reviewed version of this article. The final, definitive version of this document can be found online at Youth Violence and Juvenile Justice, published by SAGE. Copyright restrictions may apply. DOI: 10.1177/1541204010388527

\begin{tabular}{lllllllllllll} 
Age & .2 & .15 & .98 & .19 & .2 & .08 & .11 & .15 & .05 & .17 & .15 & .07 \\
Criminal father & .25 & .64 & .02 & .17 & .6 & .02 & .49 & .63 & .05 & .13 & .62 & .01 \\
Delinquency & .27 & .08 & $.21^{*}$ & & & & & & & .15 & .08 & .11 \\
Low self-control & & & & .3 & .1 & $.28^{*}$ & & & & .25 & .07 & $.23^{*}$ \\
Drug and alcohol use & & & & & & & .11 & .04 & $.19^{*}$ & .08 & .04 & $.14^{*}$ \\
& & & & & & & & & & & & \\
$R$-squared & & & & & & & & & & & & \\
\hline
\end{tabular}

*Significant at the .05 level, two-tailed. 